\title{
Effect of Grinding Parameters on the Surface Quality of Cutting Tools Made of High-Speed Low-Alloy Steels
}

\section{J. Jaworski, T. Trzepiecinski, ${ }^{1}$ and F. Stachowicz}

Faculty of Mechanical Engineering and Aeronautics, Rzeszów University of Technology, Rzeszów, Poland

${ }^{1}$ tomtrz@prz.edu.pl

The occurrence of defects caused by sharpening leads to the considerable variation of lifetime of cutting tools under identical process conditions. The loss of cutting ability of cutting tools or the change of the blade original geometry influences the quality of the surface finish as well as both dimensional and shape accuracy of workpieces. The effect of the grinding parameters on the surface finish of selected high-speed steels has been investigated. The influence of the grinding parameters has been defined especially for surface roughness, grinding forces and grinding ratio with a wide range of grinding parameters. It is found that the value of average roughness $\left(R_{a}\right)$ parameter decreases together with an increase in the grinding depth and the feed length. Furthermore, the value of $R_{a}$ increases proportionally to the grinding depth. To increase the efficiency of sharpening, it is required to increase the feed length other than the grinding depth.

Keywords: grinding, high-speed steel, surface roughness, temperature.

Introduction. Grinding is an abrasive finishing process. In the process of grinding, grains separate and form new cutting edges. Therefore, grinding is a self-sharpening process. The surface roughness is one of the most critical quality constraints for the selection of grinding factors in process planning. The surface roughness prediction in the process of grinding is the main task determining the quality of the cutting tool [1]. The other parameters of interest are the wear ratio and the volume ratio of the removed material. The quality of the surface layer is usually evaluated according to the following factors: the depth of subsurface layers with structure and/or microhardness modifications, and the surface roughness $[2,3]$.

The wear resistance of the tool material has an influence on the tool lifetime [4-7]. A certain number of important properties of tool materials such as hardness, strength, temperability and thermal conductivity is required to ensure the long lifetime of cutting tools. High-speed low-alloy steels belong to the subgroup of high-speed steels (HSS) with the composition of $\% \mathrm{~W}+1.5 \% \mathrm{Mo}<12 \%$. To ensure that the quality requirements are satisfied during the production of tools made of high-speed steels, it is very important to provide their high cutting ability [8-11]. The tool wear is one of the most important characteristics defining the accuracy of technological system of parts machining $[12,13]$. The data on lifetime of the tool made of high-speed low-alloyed steels presented in the paper are inconsistent. Determination of the machining properties and definition of the tool operational reliability as one of the elements of this system are realized using the experimental data with consideration of the blade edge wear depending on the machining time or path. However, solving the problems on the reliability of the technological system for machining parts, in particular the tool reliability (optimal planning of the tool repair or replacement), requires the knowledge of not only the expected wear value for each period of its service life, but also its distribution in accordance with the assumed tool lifetime under cutting, or distribution of the tool life and the assumed value of wear of the tool flank $(V B)$ [12-14]. The empirical dependence between the tool life $T$ and the machining parameters in the form of $T=C T / v_{c} k$ (where $C T$ is the constant equal to $T$ for $v_{c}=1 \mathrm{~m} / \mathrm{min}$ and $k$ is the 
negative slope of the $T-v_{c}$ curve) is still used for engineering calculations. It is obvious that the calculated tool lifetime is generally different from the tool life obtained from the investigation. In case the statistical parameters of the wear function of the tool flank $V B$ are determined in the investigation of the tool lifetime under cutting, it can be established that the expected value of the parameter $V B$ might be described by normal distribution during its standard service period [15-18].

The paper considers effect of grinding parameters on the surface finish of selected high-speed low-alloy steels. The influence of the grinding parameters has been determined particularly for surface roughness, grinding forces and grinding ratio with a wide range of grinding parameters.

1. Description. It is a well-known fact that the implementation of the wear function $V B=f(t)$ for high-speed low-alloy steel tools involves three wear-out periods: lapping, normal use and critical wear. Based on the statistical parameters of random functions of $V B=f(t)$, where $t$ is the time evaluated using the experimental data, it can be determined that under normal wear conditions the function of the expected wear $m V B$ is linear. In accordance with this approach the dependence of wear on the time function is more reliable since it is obtained not from the single investigation, but using the expected value of the function of $V B=f(t)$.

Figure 1 presents the effect of the machining time on the wear value $V B$. The process of machining of steel $100 \mathrm{Cr} 6$ is carried out using the turning tool made of HS18-0-1 steel. The cutting parameters are as follows: $v_{c}=10 \mathrm{~m} / \mathrm{s}, f=0.3 \mathrm{~mm} / \mathrm{rev}$, and $a_{p}=2 \mathrm{~mm}$.

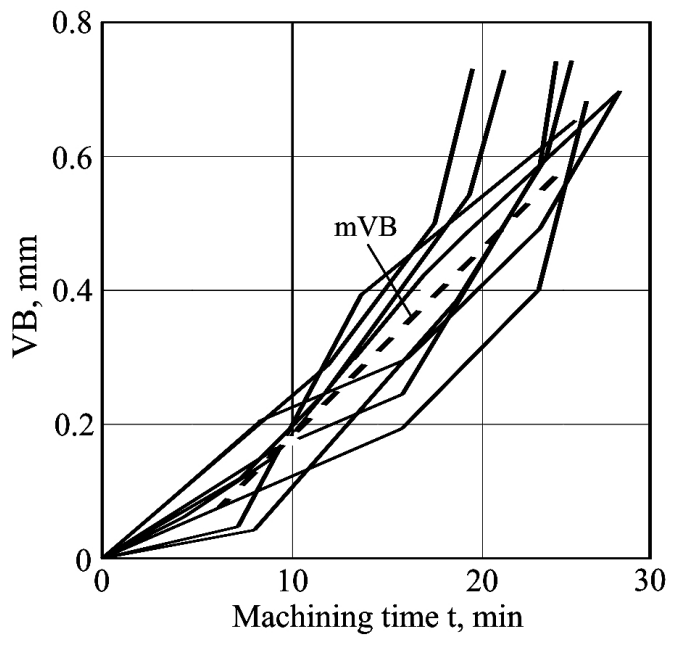

Fig. 1. Effect of the machining time on the wear value $V B$.

The experiments are performed under laboratory conditions, where heat treatment and sharpening parameters are constant. A certain number of random wear functions of $V B=f(t)$ (Fig. 1) is determined from each investigation on the test specimens. In the period of lapping, the conditions for flank wear are different from those compared to the normal wear. The temperature determined from the experiments during lapping is slightly different from the temperature at the beginning of normal wear [19]. The pressure on the tool flank while cutting using the tool after sharpening attains high values, since the force on the tool flank surface covers the small area of the contact between the tool flank and the workpiece $[20,21]$. Consequently, pressure acting on the tool flank surface is the dominant factor in determining the wear rate during lapping. This pressure is practically independent of the cutting speed. The stabilization of unit pressure on the tool flank is observed at the end of lapping. An increase in the forces acting on the tool flank surface is directly 
proportional to the size of wear $V B$. The amount of wear $V B$ is identical for the specific cutting conditions and grades of the high-speed steel with similar chemical composition (Fig. 1).

The results of investigations concerning the possibility of using high-speed low-alloy steel for punches for sheet blanking are presented in Fig. 2. The analyzed electric motor parts are made of $0.5 \mathrm{~mm}$ thick generator steel sheet type EP 470-50A coated with the insulating varnish. The blanking process is performed using high-speed press equipped with the specially constructed precision slide guide. The blanking efficiency is of 400 parts per minute.

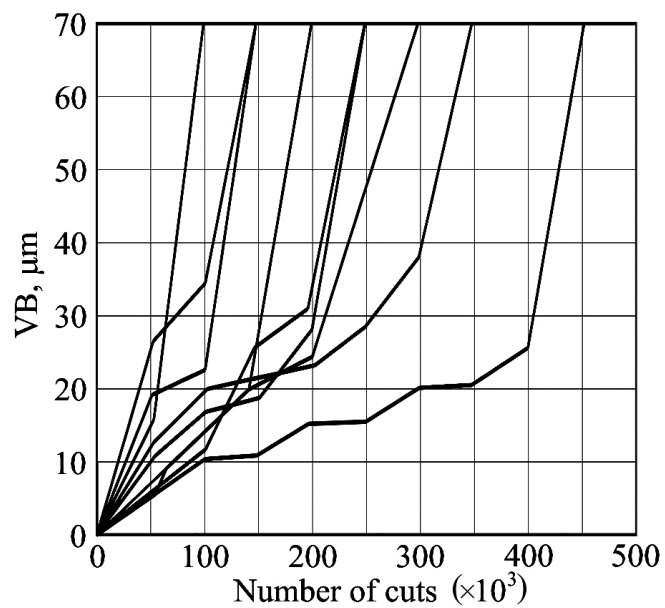

Fig. 2. Wear of the tool flank of the punches made of HS2-5-1.

The presented case of implementation of the random wear function of $V B=f(t)$ is different from that one shown in Fig. 1 and indicates the effect of the dominant factors that have an influence on the process of wear. These factors include both the elements controlling the operation conditions and the parameters of the tool initial state.

The experiments are performed using the tools controlling the conditions of heat treatment and sharpening parameters. However, as shown in Fig. 1 the implementation of the wear function of $V B=f(t)$ demonstrates its fanlike distribution. From the beginning of the tool operation different rates of the tool wear are observed. The dominant factor that significantly effects the wear dispersion and the tool lifetime is the defects due to tool sharpening. They cause the change in the nature of wear distribution. Such hazardous defects should be eliminated, and a more detailed analysis of the origins of this effect is required.

The increase in the wear rate of the tool blade with an increase of the sharpening depth shown in Fig. 3 can be explained by the greater depth of the damaged surface layer of high-speed steel containing a larger amount of austenite. Such variation of the wear function causes damage to the tool in the cutting process before sharpening. Tempering of high-speed steel tools under the wear surface conditions can also be referred to such defects. The higher the temperature on the contact surface during sharpening, the greater the depth of low-hardness layer location.

The different cutting depths at which sharpening of tools is realized cause a fanlike distribution of the wear curves. The occurrence of sharpening defects increases the wear dispersion of the cutting tool blade compared to that observed in Fig. 1. The loss of the cutting ability of abrasive tools or the change in their original shape influences the quality of the surface finish and dimensional accuracy of sharpened tools. For this reason, the abrasive tool wear is the primary criterion of evaluation of the grindability of the 


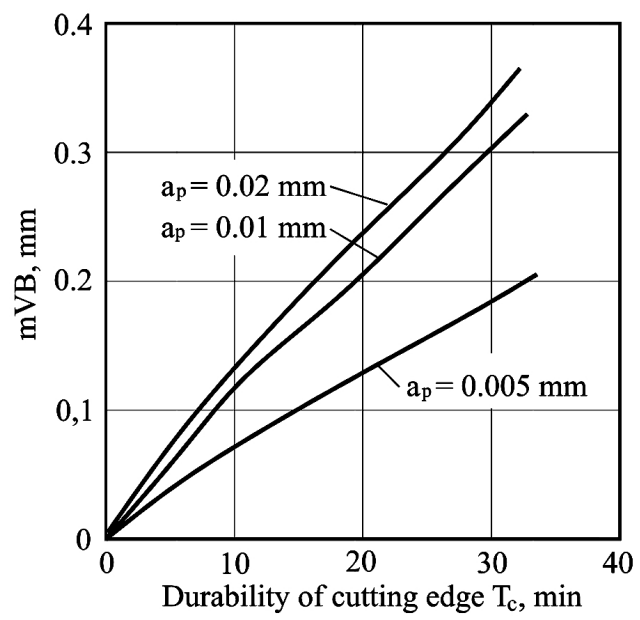

Fig. 3. Effect of the grinding depth ap on the durability of the cutting edge of pull broaches.

workpiece, which consequently has a decisive influence on the lifetime of grinding tools $[22,23]$. Grindability means the property of a material to be ground in compliance with specifications or criteria posed by the processing conditions [24].

It is a well-known fact that during sharpening of tools their residual lifetime can be varied [19]. The tool lifetime reduction due to cutting is caused by slippages on the surface of the tool point, which are formed during tool sharpening. High grinding temperatures facilitate the formation of the increased amount of secondary austenite in the surface layer of the high-speed steel $[25,26]$, which reduces the tool lifetime under cutting. Therefore, the possibility of the occurrence of these defects should be eliminated by the choice of adequate sharpening parameters.

2. Materials and Method. The specimens with dimensions of $6 \times 6 \times 65 \mathrm{~mm}$ were made of high-speed low-alloy steels. Table 1 shows their chemical composition. The heat treatment was conducted according to the recommendations from the standards.

\section{$\mathrm{T}$ a b 1 e 1}

High-Speed Low-Alloy Steel Grades: Chemical Composition and Hardness

\begin{tabular}{||c|c|c|c|c|c|c|c||}
\hline \hline \multirow{2}{*}{$\begin{array}{c}\text { Steel } \\
\text { grade }\end{array}$} & \multirow{2}{*}{$\begin{array}{c}\text { Hardness } \\
\text { (HRC) }\end{array}$} & \multicolumn{7}{|c||}{ Chemical composition (wt.\%) } \\
\cline { 3 - 8 } & & $\mathrm{C}$ & $\mathrm{W}$ & $\mathrm{Mo}$ & $\mathrm{Cr}$ & $\mathrm{V}$ & $\mathrm{Si}$ \\
\hline HS3-3-3 & 64 & 1.00 & 2.98 & 2.83 & 4.27 & 2.30 & - \\
\hline HS2-5-2 & 64 & 0.99 & 1.67 & 4.79 & 3.78 & 1.15 & - \\
\hline HS3-1-1 & $63-68$ & 1.11 & 3.35 & 1.15 & 4.65 & 1.75 & 2.05 \\
\hline HS6-5-2 & 64 & 0.82 & 5.55 & 5.13 & 4.27 & 2.06 & - \\
\hline
\end{tabular}

The investigations are carried out on the flat-surface grinder with a 95A24K disk-type grinding wheel without cooling. The influence of the grinding parameters is determined particularly for the surface roughness and the coefficient of grinding with a large range of grinding parameters: $v_{c}=20 \mathrm{~m} / \mathrm{s}, a_{p}=0.005-0.035 \mathrm{~mm}$, and $v_{f}=2-6 \mathrm{~m} / \mathrm{min}$ without cross-feed along the entire width of the specimen. After each investigation the disk-type grinding wheel is honed by diamond honing. The forces are measured using the dynamometer, whereas the surface roughness is measured using the profilograph Surtronic 3+. 
3. Results and Discussion. The results of investigations of the cutting forces depending on the longitudinal feed are shown in Fig. 4. The value of the cutting force increases with the increase in the values of longitudinal feed and cutting depth. The smallest value of cutting forces was registered in the process of grinding of HS2-5-2 and HS6-5-2 steels. In contrast, the largest grinding forces were found for HS3-3-3 and HS3-1-1 steels. The fact that the cutting forces in grinding of HS3-1-1 steel are higher than those of HS3-3-3 steel with a lower content of vanadium, can be attributed to a higher content of carbon in HS3-3-3 steel [19]. From the point of view of the surface layer quality, the improved efficiency of sharpening requires the increase of the feed length other than the grinding depth. The ultimate stresses in the surface layer were not investigated. It is known that their source is the temperature gradient on the machined surface layer. It can be assumed that for HS3-1-1 steel the level of stresses is a little higher than for HS6-5-2 steel. The development of high temperature during grinding leads to changes in the metallurgical structure and development of high internal stresses to the level where cracks can be formed [20]. As a result of the investigation it was determined that the level of ultimate stresses did not cause the formation of grinding cracks.

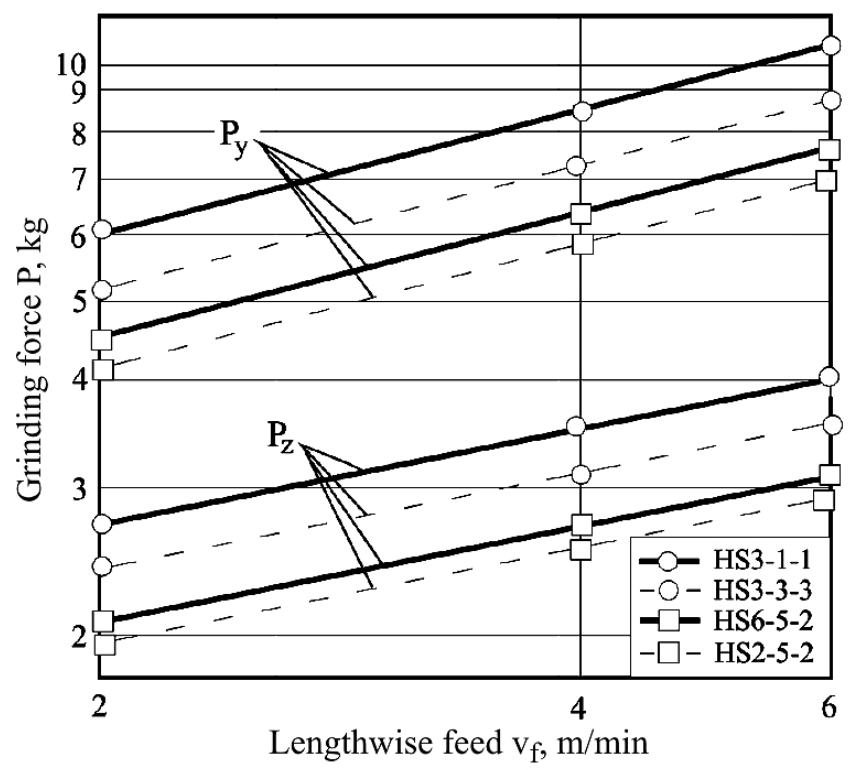

Fig. 4. Effect of the feed length on the value of grinding forces $\left(P_{y}\right.$ is the inverted grinding force and $P_{z}$ is the circumferential force).

The experimental results confirm the higher tendency to structural modifications of HS3-1-1 steel during grinding. The surface roughness is a very important parameter for the machined surface quality. The results of the measurement of the value of $R_{a}$ are presented in Figs. 5 and 6. No substantial differences in the surface finish of the selected steel grades were observed: it decreases with the grinding depth and feed length, in each case. The investigated the differences in the surface finish have no effect on the machinability of tools. Kiyak [27] has found that an increase of the workpiece speed produces a lower surface roughness in dry grinding. It was also found that a higher feed rate increases the surface roughness. Matsou [28] has reported that an increase in the material removal rate produces a higher surface roughness. Furthermore, the results indicate that the width of the wheel do not affect the surface quality. One of the main factors influencing the surface roughness is the wheel type. 


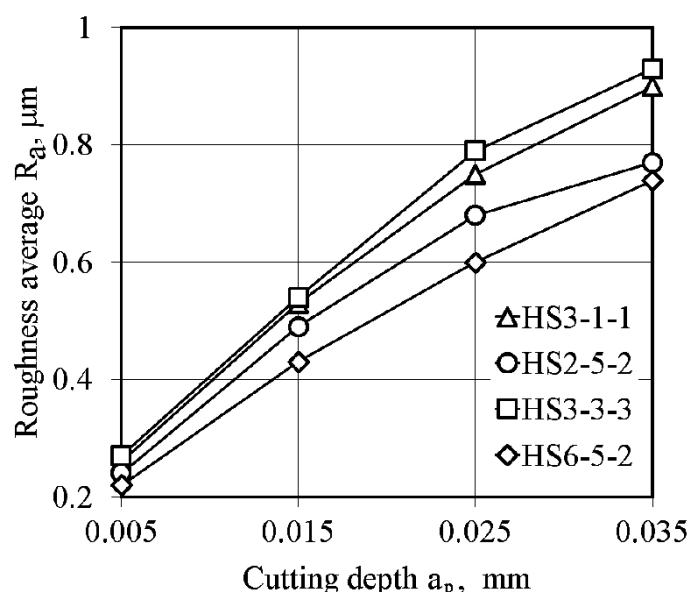

Fig. 5. Effect of the cutting depth on the average roughness value.

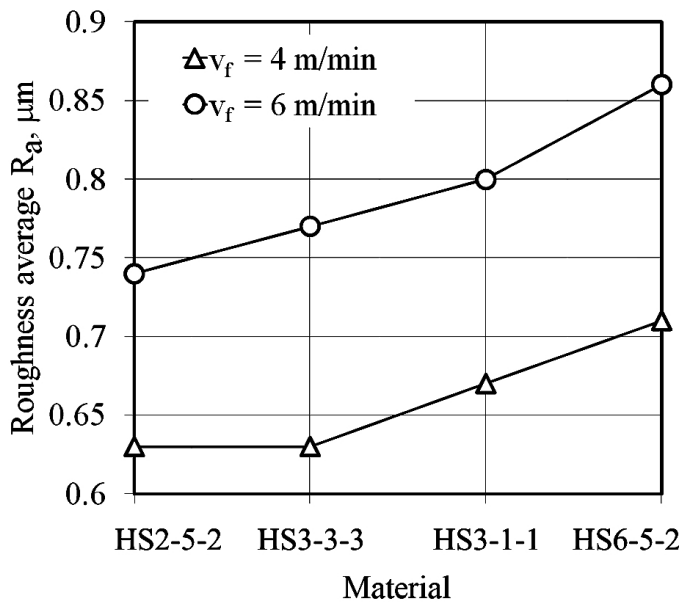

Fig. 6. Effect of the grade of high-speed low-alloy steel on the average roughness value.

Figure 7 shows the examples of two roughness profiles. Figure 7 a presents the roughness profile of HS6-5-2 $\left(a_{p}=0.005 \mathrm{~mm}\right.$ and $\left.v_{f}=2 \mathrm{~m} / \mathrm{min}\right)$. In this case, the smallest value of $R_{a}$ was observed considering all the tested specimens. Figure $7 \mathrm{~b}$ presents the roughness profile of steel HS2-5-2. In that case, the value of $R_{a}$ was $0.63 \mu \mathrm{m}$ $\left(a_{p}=0.015 \mathrm{~mm}\right.$ and $\left.v_{f}=4 \mathrm{~m} / \mathrm{min}\right)$.

The investigations of the influence of the grinding depth in the process of sharpening of pull broaches on their wear demonstrate a fanlike distribution of tooth wear. Furthermore, an increase in the wear rate with the grinding depth is observed. An increase in damage during sharpening of the surface layer of high-speed steel can be explained by a large amount of secondary austenite.

The investigations on the type of wear of the grinding wheels [29, 30] suggest that their wear is primarily dependent on the properties of the workpiece, abrasive, cutting forces, temperature, length of the contact zone, and contact time. An increase in the grinding wheel width at the constant crossfeed does not produce any noticeable changes of the abrasive grain wear intensity. Authors [31] has concluded that an increase in the grinding wheel hardness, which does not considerably influence the abrasive grains wear, causes a significant reduction of the grinding wheel wear due to bond spalling. 

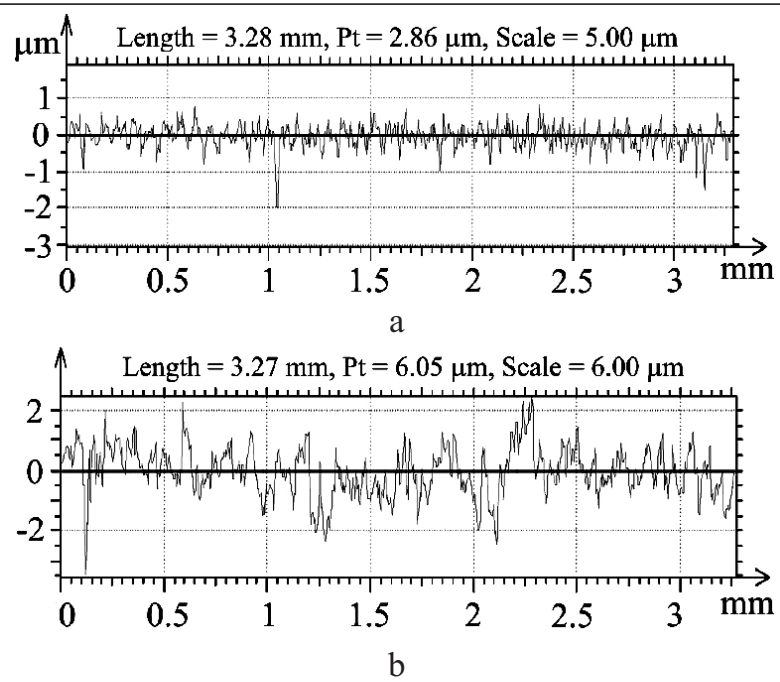

Fig. 7. Roughness profiles of HS6-5-2 (a) $\left(R_{a}=0.22 \mu \mathrm{m}\right)$ and HS2-5-2 (b) $\left(R_{a}=0.63 \mu \mathrm{m}\right)$.

Conclusions. Depending on the cutting conditions, the period of normal wear of the blade manifests different wear values $V B$ and various periods of lapping. Depending on the adopted wear criterion and the cutting process conditions, the lapping time taken to attain the end of the tool lifetime could be quite significant. The dominant factor controlling the wear rate in the period of lapping was found to be the pressure on the tool flank surface, which is practically independent of the cutting speed. At the end of the period of lapping, the stabilization of the unit pressure on the tool flank was observed. The increase in the forces acting on the tool flank was directly proportional to the value of wear $V B$. The fanlike function of wear distribution is often the result of the effect of defects from tool sharpening, which can lead to the increased wear dispersion of the tool under cutting.

The results of investigations of the grinding properties of HS2-5-2 steel show that the proper selection of the chemical composition makes it possible to improve the grinding properties of high-speed low-alloy steels. The temperature rise during sharpening is the one of the main phenomena affecting the tool surface layer quality. Therefore, application of borazon abrasive disks or suitable grinding fluid can effectively reduce the temperature during tool sharpening.

1. S. P. Sagar, G. V. S. Murthy, T. K. Das, et al., "Surface wave based ultrasonic technique for finding the optimal grinding condition of high speed steel (HSS) work rolls," Steel Res. Int., 84, No. 2, 163-168 (2013).

2. I. Ebrahimzadeh and F. Ashrafizadeh, "A comparative study of surface deformation and quality of brass workpiece in contact with coated dies by pin-on-disc testing," Int. J. Adv. Manuf. Tech., 77, No. 1, 609-620 (2015).

3. T. L. B. Tseng and Y. J. Kwon, "Characterization of machining quality attributes based on spindle probe, coordinate measuring machine, and surface roughness data," J. Comput. Des. Eng., 1, No. 2, 128-139 (2014).

4. J. A. Arsecularatne, L. C. Zhang, and C. Montross, "Wear and tool life of tungsten carbide, PCBN and PCD cutting tools," Int. J. Mach. Tool Manu., 46, No. 5, 482-491 (2006).

5. M. Sadilek, J. Dubsky, Z. Sadilkova, and Z. Poruba, "Cutting forces during turning with variable depth of cut," Perspect. Sci., 7, 357-363 (2016). 
6. M. Sadilek, J. Kratochvil, J. Petru, et al., "Cutting tool wear monitoring with the use of impedance layers," Tehnicki Vjesnik/Technical Gazette, 21, No. 3, 639-644 (2014).

7. T. Bakša, T. Kroupa, P. Hanzl, and M. Zetek, "Durability of cutting tools during machining of very hard and solid materials," Procedia Eng., 100, 1414-1423 (2015).

8. A. M. El-Rakayby and B. Mills, "On the microstructure and mechanical properties of high-speed steels," J. Mater. Sci., 23, No. 12, 4340-4344 (2013).

9. B. Wang, Z. Liu, Q. Song, et al., "Proper selection of cutting parameters and cutting tool angle to lower the specific cutting energy during high speed machining of 7050-T7451 aluminum alloy," J. Clean. Prod., 129, 292-304 (2016).

10. I. S. Cho, A. Amanov, and J. D. Kim, "The effects of AlCrN coating, surface modification and their combination on the tribological properties of high speed steel under dry conditions," Tribol. Int., 81, 61-72 (2015).

11. M. Bonek, "The investigation of microstructures and properties of high speed steel HS6-5-2-5 after laser alloying," Arch. Metall. Mater., 59, No. 4, 1647-1651 (2014).

12. B. Dolinšek, J. Šuštaršič, and J. Kopač, "Wear mechanisms of cutting tools in high-speed cutting processes," Wear, 250, No. 1-12, 349-356 (2001).

13. V. S. Sharma, S. K. Sharma, and A. K. Sharma, "Cutting tool wear estimation for turning," J. Intell. Manuf., 19, No. 1, 99-108 (2008).

14. S. Thamizhmanii and S. Hasan, "Effect of tool wear and forces by turning process on hard AISI $440 \mathrm{C}$ and SCM 440 materials," Int. J. Mater. Form., 2, No. 1, 531-534 (2009).

15. G. Boothroyd and W. A. Knight, Fundamentals of Machining and Machine Tools, 3rd edn, CRC Press, Taylor \& Francis Group, Boca Raton-London-New York (2006).

16. J. Hu and Y. K. Chou, "Characterizations of cutting tool flank wear-land contact," Wear, 263, No. 7-12, 1454-1458 (2007).

17. J. Jaworski and T. Trzepiecinski, "Research on durability of the turning tools made of high-speed low-alloy steels," Kovove Materialy/Metallic Materials, 54, No. 1, 17-25 (2016).

18. Z. Pálmai, "Proposal for a new theoretical model of the cutting tool's flank wear," Wear, 303, No. 1-2, 437-445 (2013).

19. W. A. Sinopalnikow and S. N. Grigoriew, Reliability and Diagnosis of Technological Systems [in Russian], MSTU Stankin, Moscow (2003).

20. N. V. Azarova, P. G. Matyukha, and V. V. Poltavets, "The specific cost of the surface grinding of vanadium high-speed steel with superabrasive wheels," J. Superhard Mater., 30, No. 2, 122-127 (2008).

21. B. Pal, A. K. Chattopadhyay, and A. B. Chattopadhyay, "Performance study of brazed type cBN grinding wheel on hardened bearing steel and high speed steel," Int. J. Precis. Eng. Man., 13, No. 5, 649-654 (2012).

22. F. Halila, C. Czarnota, and M. Nouari, "A new abrasive wear law for the sticking and sliding contacts when machining metallic alloys," Wear, 315, No. 1-2, 125-135 (2014).

23. M. Urbaniak, "Effect of the conditioning of CBN wheels on the technological results of HS 6-5-2 steel grinding," Arch. Civ. Mech. Eng., 6, No. 2, 31-39 (2006).

24. J. P. Davim, Machining of Metal Matrix Composites, Springer-Verlag, London (2012).

25. M. Neslušan, I. Mrkvica, R. Čep, and P. Raos, "Heat distribution when nickel alloy grinding," Tehnicki Vjesnik/Technical Gazette, 19, No. 4, 947-951 (2012). 
26. K. H. Prabhudev, Handbook of Heat Treatment of Steels, Tata McGraw-Hill Publishing, New Delhi (2008).

27. M. Kiyak, O. Cakir, and E. Altan, "A study on surface roughness in external cylindrical grinding," in: Proc. of the 12th Int. Sci. Conf. on Achievements in Mechanical \& Materials Engineering (Gliwice-Zakopane, Poland, 2003), pp. 459462.

28. T. Matsou, K. Matsubara, T. Morita, and H. Tsuwa, "Influence of working parameters in constant-load heavy grinding," CIRP Ann.-Manuf. Techn., 32, No. 1, 233-236 (1983).

29. J. Borkowski, Wear and Durability of Grinding Wheels, PWN, Warsaw (1990).

30. E. Brinksmeier, C. Heinzel, and M. Wittmann, "Friction, cooling and lubrication in grinding," CIRP Ann.-Manuf. Techn., 48, No. 2, 581-598 (1999).

31. J. Borkowski and P. Borkowski, "The influence of elementary effects on grinding wheel wear," Arch. Civ. Mech. Eng., 2, No. 1-2, 21-34 (2002).

Received 10. 08. 2016 